\title{
Input-Specific Critical Periods for Experience-Dependent Plasticity in Layer 2/3 Pyramidal Neurons
}

\author{
Jing A. Wen and Alison L. Barth \\ Department of Biological Sciences and Center for the Neural Basis of Cognition, Carnegie Mellon University, Pittsburgh, Pennsylvania 15213
}

Critical periods for experience-dependent plasticity have been well characterized within sensory cortex, in which the ability of altered sensory input to drive firing rate changes has been demonstrated across brain areas. Here we show that rapid experience-dependent changes in the strength of excitatory synapses within mouse primary somatosensory cortex exhibit a critical period that is input specific and mechanistically distinct in layer $2 / 3$ pyramidal neurons. Removal of all but a single whisker [single whisker experience (SWE)] can trigger the strengthening of individual glutamatergic synaptic contacts onto layer $2 / 3$ neurons only during a short window during the second and third postnatal week. At both layer 4 and putative 2/3 inputs, SWE-triggered plasticity has a discrete onset, before which it cannot be induced. SWE synaptic strengthening is concluded at both inputs after the beginning of the third postnatal week, indicating that both types of inputs display a critical period for experience-dependent plasticity. Importantly, the timing of this critical period is both delayed and prolonged for layer $2 / 3-2 / 3$ versus layer $4-2 / 3$ excitatory synapses. Furthermore, plasticity at layer $2 / 3$ inputs does not invoke the trafficking of calcium-permeable, GluR2-lacking AMPA receptors, whereas it sometimes does at layer 4 inputs. The dissociation of critical period timing and plasticity mechanisms at layer 4 and layer $2 / 3$ synapses, despite the close apposition of these inputs along the dendrite, suggests remarkable specificity for the developmental regulation of plasticity in vivo.

\section{Introduction}

Layer 2/3 neurons are major integrators of sensory input. Alterations in sensory experience can alter the properties of these neurons, increasing firing output in response to sensory stimulation (Fox, 1992; Diamond et al., 1993, 1994; Glazewski and Fox, 1996; Barth et al., 2000; Glazewski et al., 2007; Benedetti et al., 2009). This is attributable in part to potentiation of excitatory synapses from layer 4 , the input layer of the cortex, onto layer $2 / 3$ neurons (Clem and Barth, 2006; Clem et al., 2008, 2010). In addition, increased firing output after sensory stimulation may also be attributable to changes in synaptic drive from other layer $2 / 3$ neurons, which themselves are strongly interconnected (Lefort et al., 2009).

Single-whisker experience (SWE)-driven increases in whiskerevoked firing occur quickly (within $24 \mathrm{~h}$ of SWE) in young postnatal animals. In this case, increased firing output to stimulation of the single spared whisker can be localized to the spared whisker barrel column itself, as well as in surrounding barrel columns (Glazewski and Fox, 1996; Glazewski et al., 2007; Benedetti et al., 2009). In older animals, longer periods of SWE ( $>7 \mathrm{~d})$ are required to potentiate sensory-evoked firing in the spared barrel

Received Nov. 18, 2010; revised Jan. 11, 2011; accepted Jan. 18, 2011.

This work was supported by National Institutes of Health Grant DA0171- 88 (A.L.B). Thanks to Howard Seltman and Rob Kass for discussions on statistical analysis of the data, Joanne Steinmiller, Jill Guy, and Jesse Sheehan for animal care, and members of the Barth laboratory for helpful discussions.

A.L.B. has a patent pending on the fosGFP transgenic mice.

Correspondence should be addressed to Alison Barth, Department of Biological Sciences and Center for the Neural Basis of Cognition, Carnegie Mellon University, 4400 Fifth Avenue, Pittsburgh, PA 15213. E-mail: barth@cmu.edu. DOI:10.1523/JNEUROSCI.6042-10.2011

Copyright $\odot 2011$ the authors $\quad 0270-6474 / 11 / 314456-10 \$ 15.00 / 0$ column, indicating that the threshold for this plasticity is developmentally regulated.

At least part of the mechanism underlying rapid increases in sensory-evoked firing in young animals is increased excitatory drive resulting from the postsynaptic addition of AMPA receptors (AMPARs) to layer 4-2/3 synapses (Clem and Barth, 2006; Clem et al., 2008). However, in adult animals, it is unknown whether the experience-dependent strengthening of excitatory inputs onto layer $2 / 3$ neurons declines during postnatal development and might account for the reduced capacity of these neurons to exhibit SWE-induced increases in sensory-evoked responses in adult animals (Glazewski et al., 2007; Benedetti et al., 2009).

Here we show that synaptic identity controls a capacity for in vivo, experience-dependent plasticity. The rapid strengthening of layer 4-2/3 inputs by SWE has been well characterized (Clem and Barth, 2006; Clem et al., 2008, 2010). Previous work indicates that this potentiation occurs via the postsynaptic addition of calciumpermeable AMPARs (CP-AMPARs) (Clem and Barth, 2006), requiring NMDAR activation for initiation (Clem et al., 2008). Here, we show that SWE also potentiates putative layer $2 / 3-2 / 3$ synapses within the spared whisker barrel column and that the mechanisms of this in vivo plasticity are differentially regulated compared with layer 4-2/3 inputs.

Although both types of synapses exhibit developmentally regulated, experience-dependent synaptic strengthening, critical period timing is both delayed and prolonged for layer $2 / 3$ inputs compared with layer 4 inputs. Additionally, the molecular mechanisms underlying this plasticity are distinct between the two pathways. SWE is sufficient to induce the delivery of CPAMPARs at layer 4 but not layer $2 / 3$ inputs, although plasticity at 
both inputs can occur without the trafficking of CP-AMPARs. Despite the prolonged presence of ifenprodil-sensitive, NR2Bcontaining NMDARs at layer 4 inputs, these synapses display a shorter critical period than layer 2/3-2/3 inputs, which contain more NR2A. These data indicate that in vivo, a capacity for synaptic potentiation is regulated with extraordinary synaptic specificity.

\section{Materials and Methods}

Animals. Wild-type or heterozygous mice (males and females) from a fosGFP (1-3 line, C57BL/6 background) transgenic line ( fos $G F P^{+/-}$) ages postnatal day 11 (P11) to $\mathrm{P} 17$ were used. Bilateral whisker deprivation was performed in which all but the D1 whisker on one side were removed (Barth et al., 2000). Animals were returned to their home cages for $24 \mathrm{~h}$ before recording. Control animals were whisker-intact littermates of the deprived animals. Because there was no significant difference between control wild-type $\mathrm{C} 57 \mathrm{BL} / 6$ and fos $G F P^{+/-}$, data from these animals were grouped. Recordings in control animals were not restricted to the D1 barrel column, because all columns were equivalent in whiskerintact animals. The barrel column representing the "spared" D1 whisker was identified by enhanced fosGFP expression and relative position to the hippocampus in acute brain slices.

Whole-cell recording. Animals were anesthetized with isoflurane and decapitated. Coronal slices with $350 \mu \mathrm{m}$ thickness were vibratome sectioned in regular artificial CSF (ACSF) at $2-6^{\circ} \mathrm{C}$ composed of the following (mM): $119 \mathrm{NaCl}, 2.5 \mathrm{KCl}, 2.5 \mathrm{CaCl}_{2}, 1.3 \mathrm{MgSO}_{4}, 1 \mathrm{NaH}_{2} \mathrm{PO}_{4}, 26.2$ $\mathrm{NaHCO}_{3}$, and 11 glucose (equilibrated with $95 \% \mathrm{O}_{2} / 5 \% \mathrm{CO}_{2}$ ). Slices were maintained and whole-cell recordings were performed at room temperature. Somata of lower layer $2 / 3$ pyramidal neurons in barrel cortex were targeted for whole-cell recording with borosilicate glass electrodes with a resistance of 6-8 M $\mathrm{M}$. Electrode internal solution was composed of the following (in mM): 130 cesium, 10 HEPES, 0.5 EGTA, 8 $\mathrm{NaCl}, 4 \mathrm{Mg}$-ATP, and 0.4 Na-GTP, pH 7.25-7.30 (290-300 mOsm), containing trace amounts of Alexa Fluor-568. Pyramidal cell identity was confirmed after the recording session by pyramidal soma morphology and the presence of dendritic spines. Only cells with $R_{\text {series }} \leq 20 \mathrm{M} \Omega$ and $R_{\text {input }} \geq 200 \mathrm{M} \Omega$, in which changes in either measurement were $<20 \%$ were included for analysis. Stimulation of presynaptic afferents was applied at $0.1 \mathrm{~Hz}$ by placing glass monopolar electrodes in the center of layer 4 barrels or midlayer 2 pyramidal cell layer. Although this method cannot exclusively isolate layer $2 / 3$ inputs, the high density of withinlayer inputs indicates that the majority of inputs are likely to come from other layer $2 / 3$ neurons. We refer to these layer $2 / 3$ inputs as "putative" to indicate this uncertainty. Postsynaptic responses from layer $2 / 3$ pyramidal neurons within the same barrel column were recorded. Electrophysiological data was acquired by Multiclamp 700A (Molecular Devices) and a National Instruments acquisition interface. The data was filtered at 3 $\mathrm{kHz}$, digitized at $10 \mathrm{kHz}$, and collected by Igor Pro 6.0 (Wavemetrics). Extracellular simulation was controlled by a Master-8 (A.M.P.I.).

AMPA EPSC measurement and rectification index. To isolate AMPARmediated EPSCs, D-APV $(50 \mu \mathrm{M})$ and picrotoxin (Ptx) $(50 \mu \mathrm{M})$ were included to block NMDAR and $\mathrm{GABA}_{\mathrm{A}} \mathrm{R}$ activation in regular ACSF that contained $1 \mathrm{mM} \mathrm{MgSO}_{4}$. Spermine $(100 \mu \mathrm{M})$ was included in the internal solution to avoid washout of endogenous polyamines. Layer $2 / 3$ pyramidal neurons were voltage clamped at $-70 \mathrm{mV}$, and stimulus intensity was adjusted until a clear monosynaptic response (2-7 ms latency, consistent across trials for a given response) was visible for every sweep. For a series of holding potentials at $-70,-40,-20,0,20$, and $40 \mathrm{mV}, 10-20$ sweeps were collected and averaged. The peak amplitudes of the averaged current trace at each holding potential was normalized to that, at $-40 \mathrm{mV}$, based on which current-potential $(I-V)$ curve was constructed for each cell. A mean $I-V$ curve was generated by averaging across all cells in a group. Liquid junction potential (approximately $+10 \mathrm{mV}$ ) was not corrected for. Reversal potential for the AMPA-EPSC, or $E_{\text {rev }}$, was obtained for each cell from its $I-V$ curve. The rectification index (RI) was calculated based on the following formula: $\mathrm{RI}=I_{+40} /\left(40-E_{\text {rev }}\right) / I_{-40}\left(E_{\text {rev }}+40\right)$.

Evoked Sr-AMPA miniature EPSC measurement. To measure the amplitude of stimulus-evoked miniature AMPAR-EPSCs, $\mathrm{Sr}^{2+}(3 \mathrm{~mm})$ was substituted for $\mathrm{Ca}^{2+}$ in regular ACSF to drive asynchronous glutamate release. D-APV $(50 \mu \mathrm{M})$ and Ptx $(50 \mu \mathrm{M})$ were included to pharmacologically isolate AMPAR-mediated EPSCs, and $5 \mathrm{~mm}$ QX-314 (lidocaine $N$-ethyl bromide) was included in the Cs-gluconate internal solution to reduce noise in recordings of miniature events. Layer $2 / 3$ pyramidal neurons were voltage clamped at $-70 \mathrm{mV}$. The evoked response has an initial synchronous component $(\sim 50 \mathrm{~ms}$ after the stimulus artifact) that was excluded in the analysis. Isolated, asynchronous events that occurred from 50 to $500 \mathrm{~ms}$ after the stimulus were manually selected and analyzed using Minianalysis software (Synaptosoft). The detection threshold for events was set at $2 \times$ root mean square noise (usually $\sim 4-5 \mathrm{pA}$ ), and data were filtered with a low-pass filter at $1 \mathrm{kHz}$. Approximately 100 random events were selected for each cell and then grouped for each condition. Comparisons were made between groups. Averaged traces for each experimental condition were obtained by grouping average traces from selected events for all cells.

NMDA-EPSC measurement and ifenprodil sensitivity. To pharmacologically isolate NMDAR-mediated EPSCs, 1,2,3,4-tetrahydro-6-nitro2,3-dioxo-benzo[f]quinoxaline-7-sulfonamide hydrate $(5 \mu \mathrm{M})$ and Ptx $(50 \mu \mathrm{M})$ were included in the bath solution (regular ACSF). Cells were held at $+40 \mathrm{mV}$, and synaptic EPSCs were collected in voltage-clamp mode. A single-exponential function was fit to the average NMDA-EPSC trace from its peak to $200 \mathrm{~ms}$ after the stimulus onset and a decay constant $\tau$ was determined from the fit. To assess the content of NR2B-containing NMDARs, ifenprodil $(10 \mu \mathrm{M})$, an NR2B specific antagonist was infused to the recording chamber locally because the action of ifenprodil was poorly reversible (Kumar and Huguenard, 2003) after a stable baseline was achieved for $5 \mathrm{~min}$. A post response was collected $5 \mathrm{~min}$ after infusion to allow complete diffusion.

Ratio of AMPAR/NMDAR-mediated EPSCs. Cells were held at -70 and $+40 \mathrm{mV}$ to isolate the AMPA-EPSC and NMDA-EPSC, respectively. The amplitude of the AMPA-EPSC was taken at the peak of synaptic response recorded at $-70 \mathrm{mV}$, and the amplitude of the NMDA-EPSC was taken $50 \mathrm{~ms}$ after the stimulus onset at $+40 \mathrm{mV}$, when the AMPAEPSC component decays to baseline. A ratio of AMPA-EPSC and NMDA-EPSC amplitudes were obtained from these values.

Dual-pathway recordings. For experiments in which synaptic responses from layer $4-2 / 3$ and layer $2 / 3-2 / 3$ excitatory pathways were recorded from the same cell, two stimulating electrodes were set up in layer 4 and layer 2 of the same barrel column. Stimulation frequency was the same for both pathways $(0.1 \mathrm{~Hz})$.

Statistics. For all non-pairwise comparisons, a nonparametric MannWhitney $U$ test (two-tailed) was used. For all pairwise comparisons (dual-pathway and ifenprodil sensitivity experiments), a paired Student's $t$ test was used. For Sr-EPSC amplitude comparisons between control and SWE conditions (see Figs. 1, 3), cell values were averaged within an animal and then averaged across animals for that age group. To determine whether SWE-induced plasticity was developmentally regulated, mean Sr-EPSC amplitudes were statistically evaluated using a Mann-Whitney $U$ test, followed by a Bonferroni correction (groups $\mathrm{P} 12-\mathrm{P} 14$ for layer 4-2/3 synapses, P13-P16 for layer 2/3-2/3 synapses) to compare control and SWE conditions. The corrected $p$ value was derived from the Mann-Whitney $p$ value multiplied by the number of possible contiguous groupings ( 15 in this study).

\section{Results}

\section{A critical period for experience-dependent plasticity at layer 4-2/3 synapses}

Layer 4 excitatory neurons make multiple contacts onto layer $2 / 3$ pyramidal cells, providing strong and reliable input that varies with stimulus strength. To assess the mean amplitude of an individual synaptic contact, we stimulated layer 4 neurons in ACSF in which $\mathrm{Ca}^{2+}$ had been replaced with $\mathrm{Sr}^{2+}$ to desynchronize neurotransmitter release (Goda and Stevens, 1994; Abdul-Ghani et al., 1996; Xu-Friedman and Regehr, 1999) while recording the response of layer $2 / 3$ neurons (Fig. $1 A$ ). Under these conditions, the delayed occurrence of AMPAR-mediated miniature EPSCs (mEPSCs) can be observed (Fig. $1 \mathrm{D}$ ), events that are thought to reflect the release of a single neurotransmitter vesicle. 
Previous work from the laboratory has shown that $24 \mathrm{~h}$ of SWE results in an increase in the mean amplitude of AMPAREPSCs evoked by layer 4 stimulation in the presence of $\mathrm{Sr}$ ( $\mathrm{Sr}$-EPSCs) compared with control undeprived animals. To determine whether the magnitude of plasticity at layer 4-2/3 synapses was developmentally regulated, we initiated $24 \mathrm{~h}$ of SWE at different postnatal ages. To identify the cortical representation of the spared whisker, acute brain slices from fosGFP transgenic mice that had undergone SWE were prepared (Fig. $1 C$ ), and stimulating and recording electrodes were placed in the spared barrel column.

Twenty-four hours of SWE from P10 to P11 was insufficient to induce an increase in the quantal amplitude of AMPAR-EPSCs (control, $10.8 \pm 0.81 \mathrm{pA}$ vs SWE, $9.0 \pm 0.70 \mathrm{pA}$ ) (Fig. $1 E, F$ ). At this time, the overall input strength from layer 4 to layer $2 / 3$ is weak (Lendvai et al., 2000; Maravall et al., 2004). However, a single day later, SWE was sufficient to drive a significant increase in the amplitude of layer 4-2/3 excitatory (P12 control, $9.5 \pm 0.48$ vs SWE, $12.6 \pm 0.61 \mathrm{pA})$. SWE-induced increases in excitatory synaptic strength were significant at P13 and P14 (Fig. 1E,F). However, at P15, SWE was no longer capable of triggering an increase in Sr-EPSC amplitude (P15 control, $10.5 \pm 0.32$ vs SWE, $10.4 \pm 0.39$ ), and this result was observed for all subsequent ages examined (Fig. $1 F$ ). Thus, we find that, at layer 4-2/3 synapses, rapid experience-dependent increase in synaptic strength can be induced only for a short time window at the end of the second postnatal week, from P12 to P14 (P12-P14 control vs SWE, $p=0.0001$ with Bonferroni correction).

\section{CP-AMPARs and SWE-induced plasticity}

We and others have shown that addition of CP-AMPARs can occur during potentiation of excitatory synapses, both in vivo and in vitro (Shi et al., 1999; Hayashi et al., 2000; Zhu et al., 2000; Takahashi et al., 2003; Bellone and Lüscher, 2006; Clem and Barth, 2006; Plant et al., 2006; Matsuo et al., 2008). Under control, undeprived conditions, layer 4-2/3 synapses show a linear $I-V$ relationships (Fig. $2 B, C$ ) and slow EPSC decay kinetics (Fig. $2 G, H)$, characteristic of GluR2-containing AMPARs. After $24 \mathrm{~h}$ of SWE, AMPARs with fast decay kinetics and rectifying $I-V$ relationships characteristic of CP-AMPARs can be detected (Clem and Barth, 2006) (P13 RI, control, 0.81 \pm 0.06 ; SWE, $0.57 \pm 0.05$ ) (Fig. 2C,F; see also Sr-EPSC decay time in $G, H$ ). Because CPAMPARs possess a long C-terminal tail that promotes activitydependent mobilization to the synapse (Sheng and Lee, 2001) and also exhibits higher single-channel conductance than calciumimpermeable AMPARs (Swanson et al., 1997), trafficking of these receptors to the excitatory inputs can increase synaptic strength in several ways. Furthermore, the developmental reg-
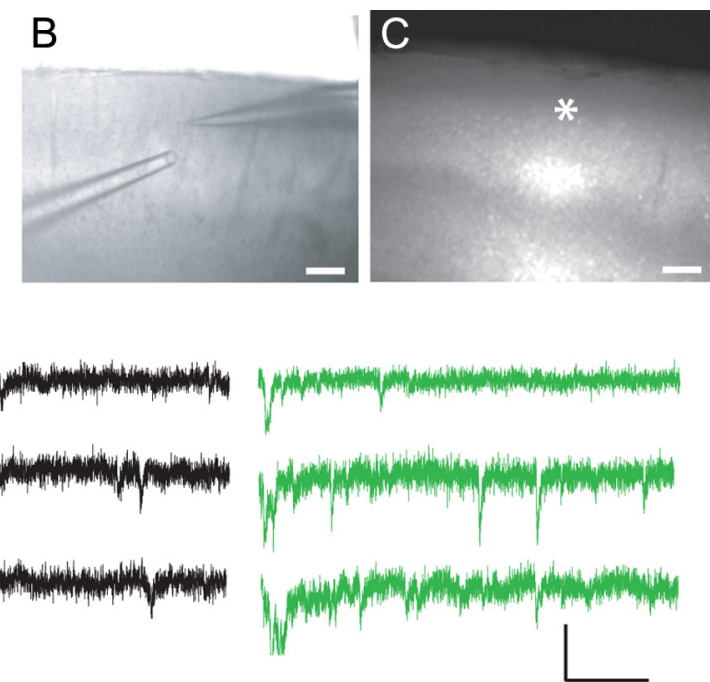

$\mathrm{F}$

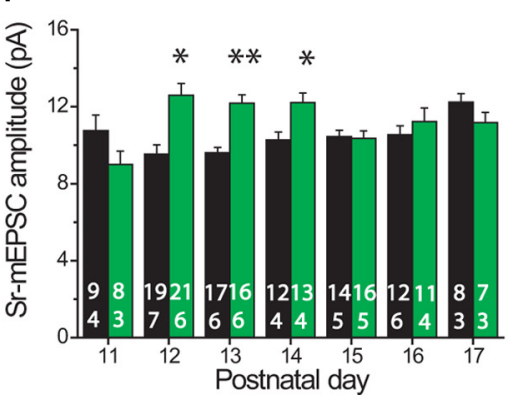

Figure 1. SWE induces rapid increase in evoked $\mathrm{Sr}-\mathrm{mEPSC}$ amplitude at layer 4-2/3 excitatory synapses only during a short developmental window. $\boldsymbol{A}$, Schematic of stimulating and recording electrode placement for measuring layer 4-2/3 Sr-mEPSCs. $\boldsymbol{B}$

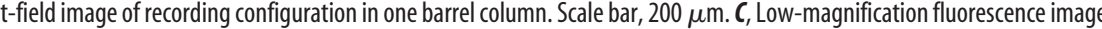
(barrel column with strong signal located in layer 4 (barrel column indicated with asterisk). Scale bar, $200 \mu \mathrm{m}$. D, (green) animals at layer 4-2/3 synapses. The number of cells (top) and animals (bottom) used are indicated on the ba

ulation of CP-AMPARs has been noted in previous studies (Kumar et al., 2002; Brill and Huguenard, 2008). Thus, it was tempting to speculate that SWE-induced potentiation of layer 4-2/3 synapses might require CP-AMPARs, and the unavailability of these AMPARs might trigger the closure of the critical period.

To determine whether the end of rapid, SWE-induced plasticity was associated with a reduction in the SWE-dependent trafficking of CP-AMPARs, we evaluated the electrophysiological properties of potentiated layer 4-2/3 inputs at P14 after SWE. Surprisingly, we observed robust potentiation even in the absence of CP-AMPARs (P14 RI for control, $0.81 \pm 0.07$ vs SWE, $0.86 \pm 0.13$ ) (Fig. $2 D-F$; see also $G, \mathrm{H})$. Indeed, increased rectification of AMPAR-EPSCs after SWE was prominent for only 1 postnatal day, at P13. These data indicate that strong experiencedependent synaptic strengthening can occur without the trafficking of CP-AMPARs and that a decline in the availability of CP-AMPARS is unlikely to explain the close of the critical period at layer $4-2 / 3$ synapses.

\section{Experience-dependent potentiation of layer 2/3-2/3 excitatory synapses}

In our studies, to characterize SWE-induced changes in sensoryevoked firing across development, the rapid potentiation of firing 
A

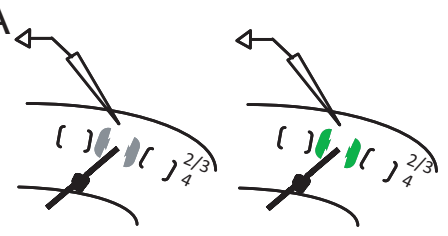

C

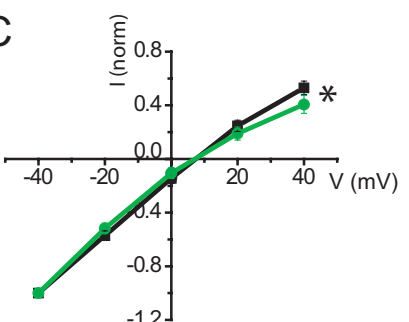

E
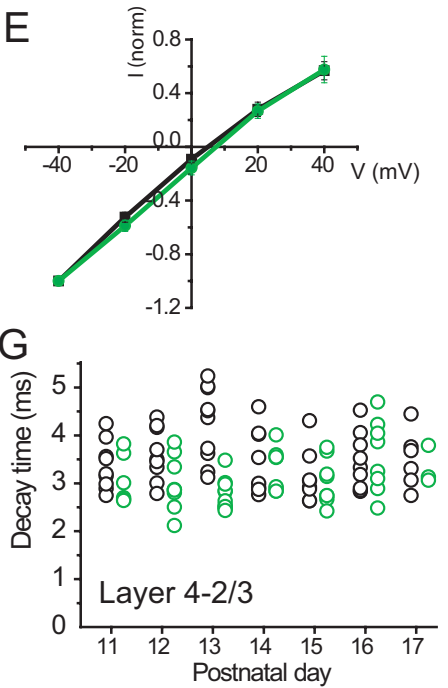

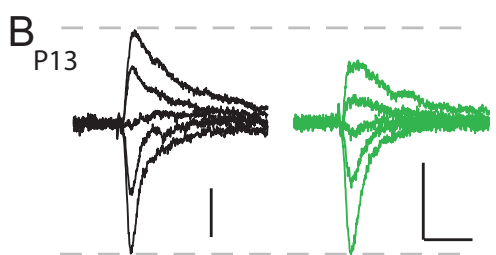

D
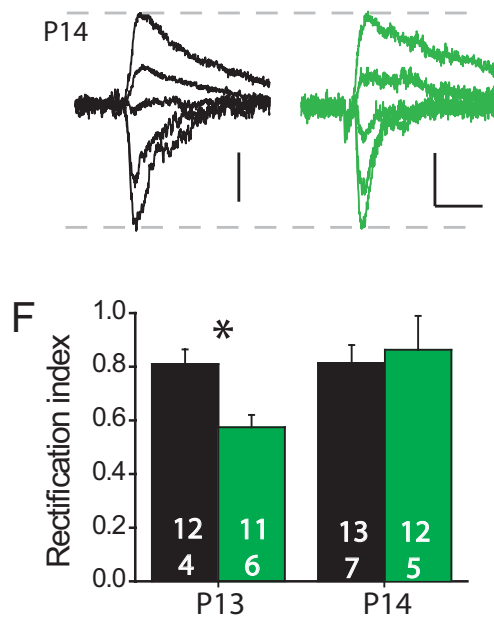

H

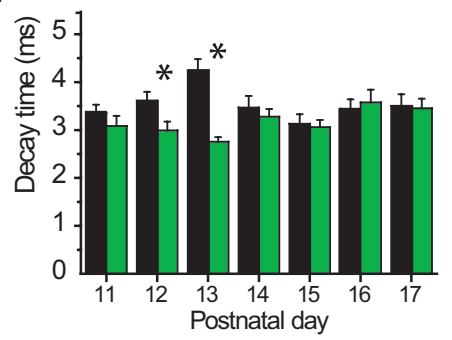

Figure 2. SWE drives (P-AMPARs to layer 4-2/3 synapses only at P13 but not P14. $A$, Schematics of electrode placement for control (black) and SWE-treated (green) tissue at layer 4-2/3 synapses. $\boldsymbol{B}$, Example layer 2/3 pyramidal cells from a P13 control (black) and an SWE-treated (green) animal showing layer 4-evoked AMPA-EPSCs recorded at $-40,-20,0,+20$, and $+40 \mathrm{mV}$ holding potentials. Calibration: 20 pA, 20 ms. The SWE cell shows clear EPSC rectification at positive holding potentials compared with the control cell. $\boldsymbol{C}$, Normalized AMPA-EPSC amplitude (to amplitude at $-40 \mathrm{mV}$ ) as a function of holding membrane potential (I-V curve) for control and SWE animals at P13. D, Example cells from a P14 control and an SWE animal as in $\boldsymbol{B}$ ). Calibration: 10 pA, 20 ms. E, I-V curves for control and SWE at P14 as in C. F, Rectification index for control and SWE animals at P13 and P14 at layer 4-2/3 synapses. $\mathbf{G}$, Scatter plot of Sr-mEPSC decay time for control and SWE-treated animals at layer 4-2/3 pathway from P11-P17. $\boldsymbol{H}$, Mean Sr-mEPSC decay time for layer $4-2 / 3$ pathway. ${ }^{*} p<0.05$.

rates in layer $2 / 3$ neurons can be observed into the third postnatal week, although it declines soon afterward (Benedetti et al., 2009). Because this time period extends past the critical period for SWEinduced potentiation at layer 4-2/3 synapses, it is likely that other processes must be at work to facilitate increased firing output after stimulation of the spared whisker.

Previous work has not addressed whether other excitatory inputs onto layer $2 / 3$ pyramidal neurons also undergo SWEinduced increases synaptic strength. To examine whether intralaminar excitatory inputs might also show SWE-induced potentiation, AMPAR-mediated Sr-EPSCs were compared between control and SWE-treated animals. In this case, the stimulation electrode was placed in layer 2, within the same barrel column (Fig. $3 A, B)$. This form of stimulation will primarily activate intralaminar connections from other layer $2 / 3$ neurons because these neurons are densely interconnected and receive little input from other cortical layers (Lefort et al., 2009), although excitatory synapses from other areas may also be driven by this form of stimulation. Similar to layer
4-2/3 inputs, SWE assessed at P11 was not sufficient to drive increases in Sr-EPSC amplitude (control, $12.0 \pm 0.54 \mathrm{pA}$ vs SWE, $11.0 \pm 0.42 \mathrm{pA})$. However, unlike at layer 4-2/3 inputs, SWE assessed at P12 was also unable to drive a significant change in $\mathrm{Sr}-$ EPSC amplitude (control, $11.9 \pm 0.80 \mathrm{pA}$ vs SWE, $12.2 \pm 0.51 \mathrm{pA}$ ) (Fig. $3 C-E$ ).

SWE-driven increases in Sr-EPSC amplitude at these layer 2/3-2/3 inputs were first observed at P13 (control, $10.8 \pm 0.54$ pA vs SWE, $13.4 \pm 0.97 \mathrm{pA}$ ). Thus, altered sensory input in the form of SWE can drive the strengthening of intralaminar, putative layer $2 / 3-2 / 3$ inputs, although the timing of this phenomenon is distinct from that observed at layer 4-2/3 inputs.

Developmental analysis of SWE-induced changes in Sr-EPSC amplitude at layer $2 / 3-2 / 3$ synapses revealed that this plasticity was prolonged by several days compared with layer 4-2/3 synapses. At P16, SWE led to a significant increase in synaptic strength (control, $10.0 \pm 0.37 \mathrm{pA}$ vs SWE, $12.4 \pm 0.75 \mathrm{pA}$ ), $2 \mathrm{~d}$ after the closure for rapid, SWE-induced increases in the amplitude of layer 4-2/3 inputs (Fig. 3E) (P13-P16 control vs SWE, $p=0.01$ with Bonferroni correction). These results show that onset timing, duration, and end of SWE-induced plasticity are distinct for layer $4-2 / 3$ and layer 2/3-2/3 synapses and indicate that experience-dependent plasticity is regulated in an input-specific manner.

\section{Potentiated layer 2/3-2/3 synapses do not mobilize \\ CP-AMPARs}

To determine whether plasticity at layer $2 / 3$ $2 / 3$ inputs was mechanistically similar to that observed at layer 4-2/3 synapses, we examined whether CP-AMPARs were present at potentiated intralaminar synapses, as had been observed for layer 4-2/3 inputs.

Analysis of AMPAR-EPSC rectification and Sr-EPSC decay kinetics suggested that CP-AMPARs were not trafficked to layer $2 / 3-2 / 3$ synapses under any conditions (Fig. $4 B-E, I$ ). Similar to layer $4-2 / 3$ inputs, no significant rectification was observed in slices from control, undeprived animals. This was also observed at P13, when SWE was effective at trafficking CP-AMPARs to layer $4-2 / 3$ synapses (Fig. $4 B, C$ ). To determine whether there might be an offset in the timing of CP-AMPAR delivery that might be later at layer 2/3-2/3 synapses, we also examined SWEinduced changes in rectification at P14. However, SWE was not associated with evidence for rectifying AMPARs at this age either (Fig. 4D,E).

To verify that this was not attributable to subtle differences in our recording conditions across different experiments, recordings were performed to directly compare rectification properties in the same cell (Fig. $4 F, G$ ). Stimulation electrodes were simultaneously placed in layer 4 and layer $2 / 3$ of the spared barrel column, and the EPSCs from the postsynaptic cell were collected 
across a range of holding potentials in the presence of D-APV and picrotoxin to pharmacologically isolate AMPAR-EPSCs. In six of eight cases, rectifying AMPAR-EPSCs could clearly be observed at layer $4-2 / 3$ but not layer $2 / 3-2 / 3$ inputs (Fig. $4 G$ ). On average, no significant increase in AMPAR rectification was observed after SWE at intralaminar inputs (Fig. $4 H$ ). Thus, we conclude that layer $2 / 3$ excitatory inputs are distinct from layer 4 in both their developmental timing and the synaptic mechanisms underlying SWE-induced plasticity.

\section{Precise, synapse-specific onset of} experience-dependent plasticity Given experimental uncertainty in gestation period and the precise timing of birth (birthdate was approximated by inspection $1-2 \times / d$ ), it is remarkable that we were able to identify a discrete time window by which layer 4 and layer $2 / 3$ inputs are differentially regulated by sensory experience. To control for potential differences between groups of animals, we undertook a second series of experiments whereby littermate control and SWEtreated animals were examined on the same postnatal day. Furthermore, both input pathways were evaluated in the same cell, providing additional strength to this method of comparison. Because SWE is capable of triggering synaptic strengthening at layer 4 but not layer $2 / 3$ inputs at $\mathrm{P} 12$, this age was selected for more extensive analysis.

Dual-pathway recordings of Sr-EPSCs from pairs of P12 control and SWEtreated littermates were performed (Fig. $5 A, B$ ). In these littermates with identical postnatal ages, SWE induced a robust and significant increase in Sr-EPSC amplitude only at layer 4 inputs (control, $9.7 \pm 0.6 \mathrm{pA}$ vs SWE, $11.7 \pm 0.4 \mathrm{pA} ; p<0.05$ by Mann-Whitney test) but not at layer $2 / 3$ inputs (control, $11.0 \pm$ $1.2 \mathrm{pA}$ vs SWE, $11.1+0.4 \mathrm{pA} ; p>0.3$ by Mann-Whitney test). In addition, stimulation in layer $2 / 3$ of adjacent, deprived barrel did not reveal any SWE-dependent change in synaptic strength, indicating that these effects are specific to the spared barrel column (Fig. 5C,D). These results are consistent with previous findings from the single pathway-stimulation recordings and strongly support the conclusion that critical period timing is regulated in an input-specific manner.

\section{NMDARs at layer 2/3-2/3 synapses contain less NR2B than layer 4 inputs}

Because developmental plasticity is associated with elevated NR2B content at thalamocortical synapses (Carmignoto and Vicini, 1992; Barth and Malenka, 2001; Lu et al., 2001), we hypothesized that the extended duration of SWE-induced plasticity at layer 2/3-2/3 inputs might be associated with increased NR2B at these connections. To assess this, we examined the ifenprodil sensitivity and decay kinetics of the pharmacologically isolated NMDAR-EPSC in control, undeprived animals at a time at which SWE was capable of inducing an increase in Sr-EPSC amplitude at both types of synapses, P13.

Layer 2/3-2/3 and layer 4-2/3 inputs were analyzed in the same postsynaptic cell, using the dual-pathway stimulation setup. At this age, NMDAR-mediated EPSCs at layer 2/3-2/3 synapses were moderately but significantly less sensitive to the NR2B-specific antagonist ifenprodil than layer 4-2/3 synapses within the same cell (percentage reduction in peak NMDAR-EPSC current at $+40 \mathrm{mV}$ for layer $2 / 3-2 / 3,51.2 \pm 5.4 \%$ vs layer $4-2 / 3,57.7 \pm$ $5.7 \%$ ) (Fig. 6C,D). Consistent with a higher NR2A content at layer 2/3-2/3 synapses, layer 2/3-2/3 NMDAR-EPSCS also displayed faster decay kinetics than those at layer $4-2 / 3$ synapses (layer $2 / 3-2 / 3 \tau=59.8 \pm 2.7 \mathrm{~ms}$ vs layer $4-2 / 3 \tau=93.3 \pm 11.4$ ms) (Fig. $6 A, B$ ). These results could not be attributed to differences in presynaptic release properties between the two pathways, because the degree of paired-pulse depression was identical at the two inputs $(0.67 \pm 0.06$ at layer $4-2 / 3$ synapses vs $0.68 \pm 0.07$ at layer $2 / 3-2 / 3$ synapses; $p>0.8$ ).

In addition to comparing the properties of NMDARs at these two different synapses, we also examined the ratio of AMPAR and NMDAR current amplitudes (A:N ratio) as an indicator of synaptic maturation (Wu et al., 1996; Isaac et al., 1997; Chiu et al., 2008). Experiments were performed by stimulating both pathways and recording from a single cell in the presence of picro- 


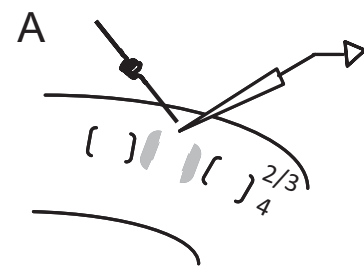

B

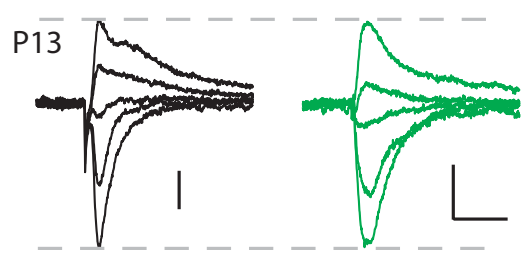

C
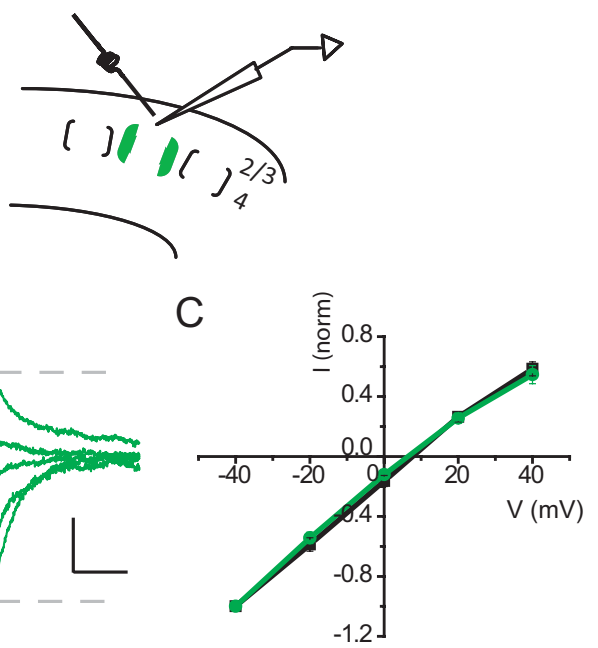

$E$
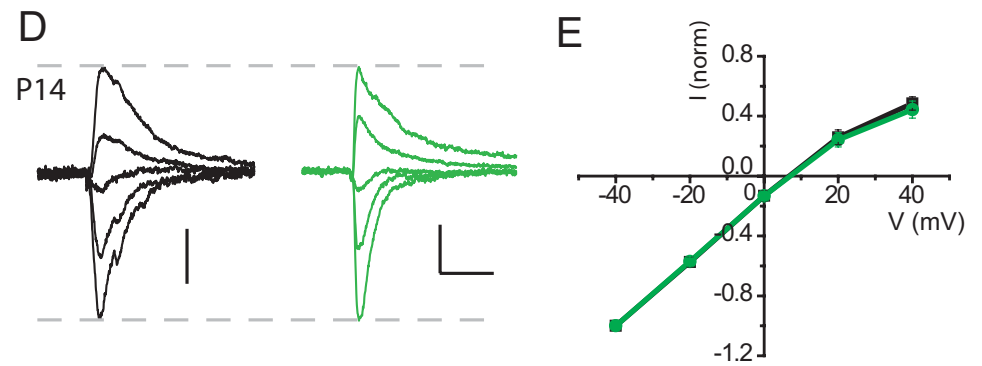

$\mathrm{F}$

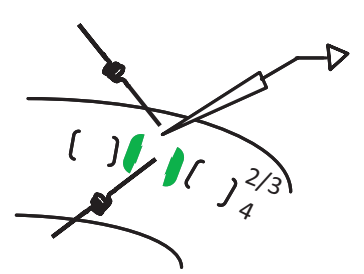

G
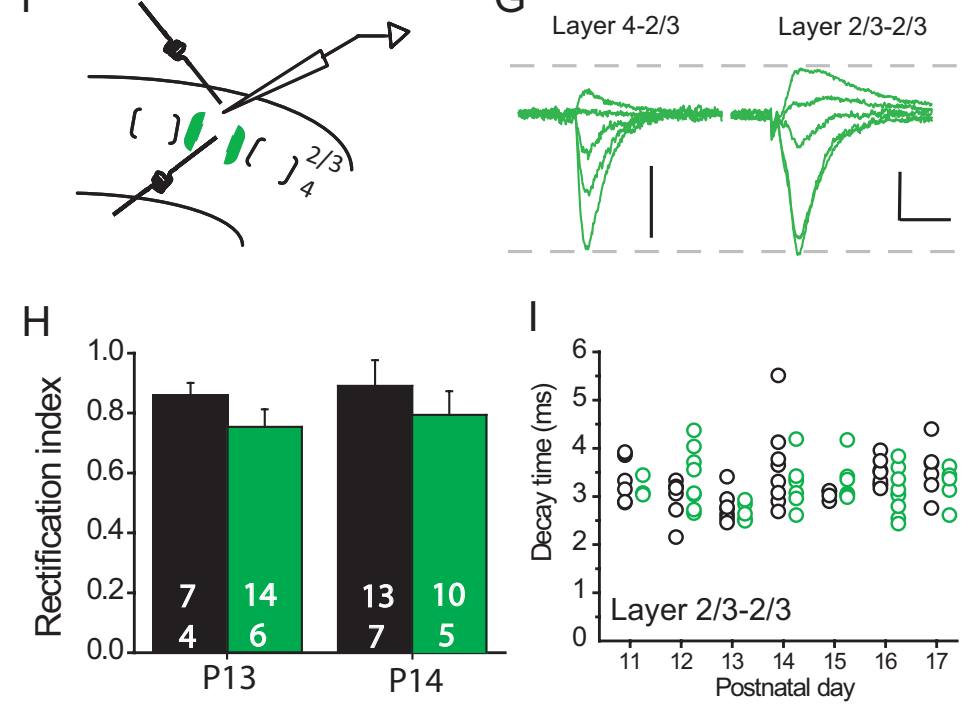

Figure 4. SWE does not drive (P-AMPARs to layer 2/3-2/3 synapses. $A$, Schematics of electrode placement for control (black) and SWE-treated (green) tissue at layer 2/3-2/3 synapses. $\boldsymbol{B}$, Example cells from P13 control and SWE animals showing layer 2/3-evoked AMPA-EPSCs at holding potentials $-40,-20,0,+20$, and $+40 \mathrm{mV}$. Calibration: $20 \mathrm{pA}, 20 \mathrm{~ms}$. C, I-V curves for control and SWE animals at P13.D, Example cells from P14 control and SWE animals as in $A$. Calibration: $30 \mathrm{pA}, 20 \mathrm{~ms}$. E, I-V curves for control and SWE animals at P14. $F$, Configuration of dual-pathway recording in SWE-treated tissue. One stimulation electrode is placed in layer 4 and the other is in layer 2 of the same barrel column while recording from the same layer $2 / 3$ neuron. $G$, Example traces (peak-scaled) from dual-pathway recordings of a P13 SWE-treated animal at holding potentials $-40,-20,0,+20$, and $+40 \mathrm{mV}$. Calibration: $30 \mathrm{pA}, 10 \mathrm{~ms}$. Layer 4-2/3 synapse shows more rectification than layer 2/3-2/3 synapse within the same postsynaptic neuron. $\boldsymbol{H}$, Rectification index for P13 and P14 control and SWE-treated animals at layer 2/3-2/3 synapses. $\boldsymbol{I}$, Scatter plot of Sr-mEPSC decay time at layer 2/3-2/3 pathway from P11-P17.

toxin to pharmacologically isolate glutamatergic currents. The A:N ratio was not significantly different at control layer $2 / 3-2 / 3$ versus layer $4-2 / 3$ synapses (P12-P13 layer $2 / 3-2 / 3,0.82 \pm 0.1$ vs layer 4-2/3, $0.85 \pm 0.07$ ) (Fig. 6E,F).
A similarity in the A: $\mathrm{N}$ ratio was observed despite a small but reproducible difference in the amplitude of control layer 2/3-2/3 Sr-EPSCs compared with layer $4-2 / 3$ synapses at the end of the second postnatal week (P13 layer 2/3-2/3, $11.2 \pm 0.7 \mathrm{pA}$ vs layer $4-2 / 3,9.9 \pm 0.4 \mathrm{pA})$ (Fig. $7 A, B$ ). This difference in Sr-EPSC amplitude is not likely to be attributable to differential electrical filtering of the EPSC signal attributable to the location of layer $2 / 3$ and layer 4 inputs along the layer $2 / 3$ pyramidal cell dendrite, because the rise and decay times for these events were identical for the two inputs (Fig. 7E). This difference in the amplitude of Sr-EPSCs did not appear to persist over time, because the two pathways became similar at later developmental time points (P14$\mathrm{P} 15$ layer $2 / 3-2 / 3,9.12 \pm 0.4 \mathrm{pA}$ vs layer $4-2 / 3,9.52 \pm 0.3 \mathrm{pA}$ ) (Fig. 7C,D for twopathway experiments in the same cell and for all values pooled across a given day from P11-P17; see also $F$ ).

Together, these data provide additional support for the finding that different excitatory synapses onto the same layer $2 / 3$ neuron can display markedly different properties. In addition, these findings indicate that relatively high NR2B content is linked to a capacity for experiencedependent plasticity in vivo, consistent with previous developmental studies.

\section{Discussion}

Here we have used SWE-induced potentiation to evaluate how plasticity at different synapses can be regulated by in vivo sensory experience, identifying pathwayspecific critical periods for excitatory synaptic strengthening in layer $2 / 3$ pyramidal neurons. Compared with layer 2/3-2/3 synapses, layer $4-2 / 3$ synapses show an earlier and shorter period during which alteration in sensory input induced by the removal of all but a single whisker can increase synaptic strength. The timing of this critical period, for SWE initiated at $\mathrm{P} 11-\mathrm{P} 13$, is similar to what has been observed for the effects of sensory deprivation on layer $2 / 3$ neurons in rat barrel cortex for dendritic spine motility (Lendvai et al., 2000) and the maturation of sensory-evoked responses in vivo (Stern et al., 2001; Shoykhet et al., 2005). In addition, the maturation of intrinsic firing properties in layer $2 / 3$ neurons has been localized to this brief developmental window (Maravall et al., 2004).

In comparison, we found a delayed and prolonged period for experience-dependent plasticity at layer $2 / 3-2 / 3$ synapses. Given that mice mature slightly more quickly (based on different gestation periods and time to sexual 
A

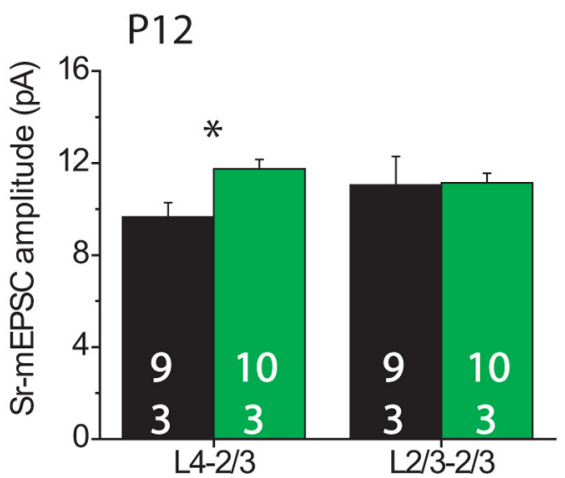

B
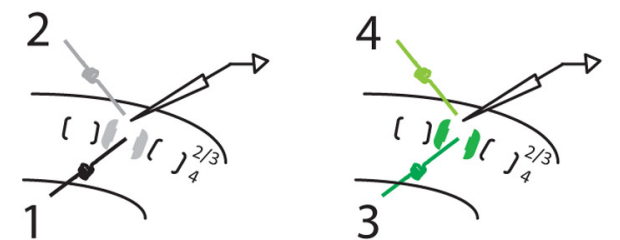

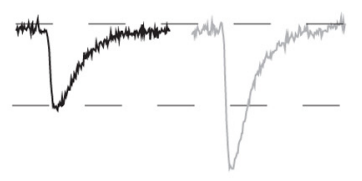

1

C

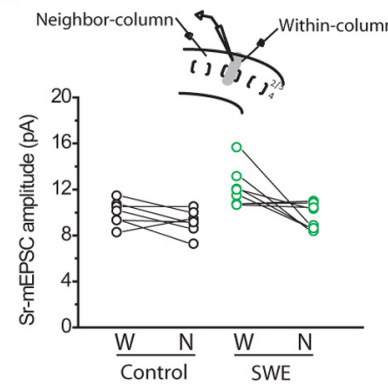

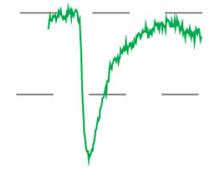

3

$\mathrm{D}$

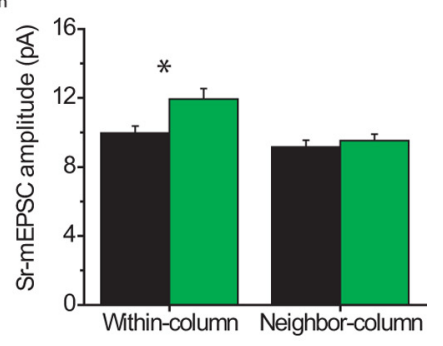

A
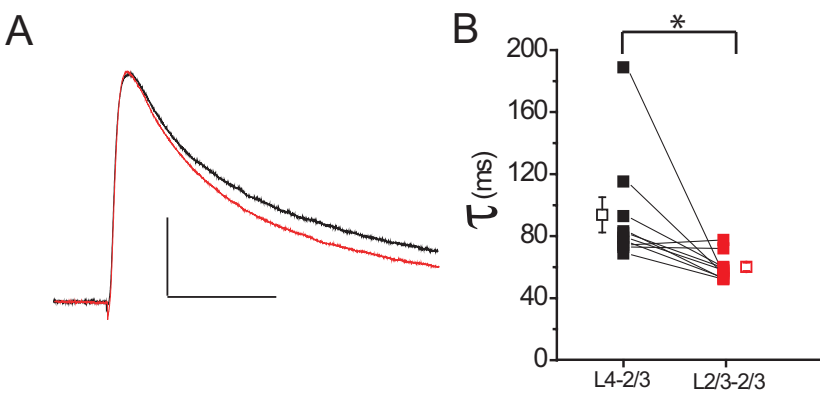

C

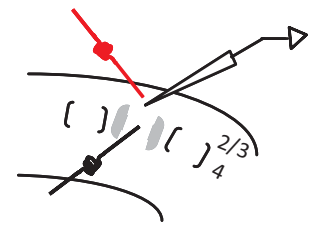

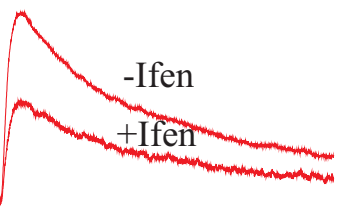

$E$

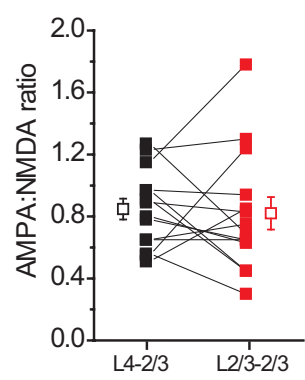

F
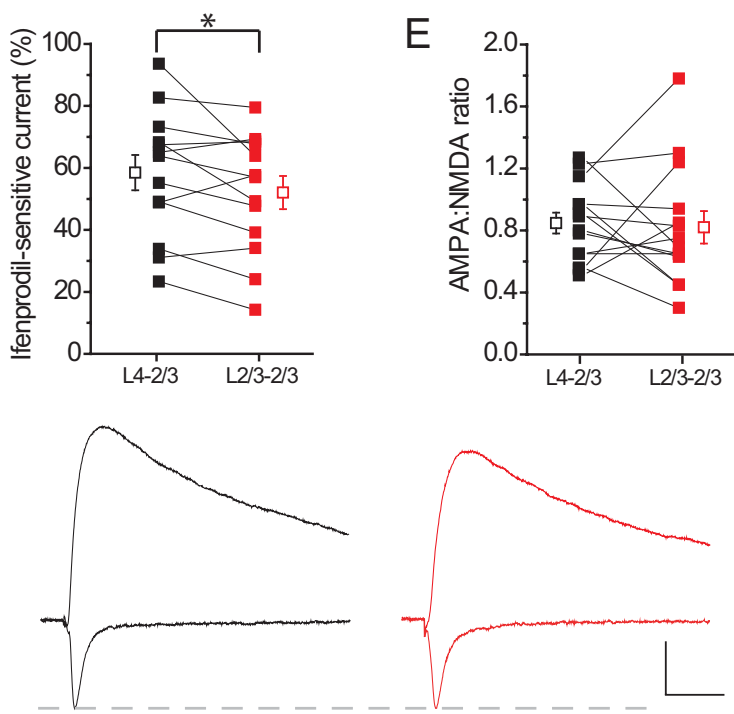

Figure 6. NMDAR properties are different between layer 4-2/3 and layer 2/3-2/3 excitatory synapses. $A$, Peak-scaled averaged traces of NMDA-EPSC recorded at $+40 \mathrm{mV}$ for layer 4-2/3 (black) and layer 2/3-2/3 (red) pathways. Calibration: 100 pA, $100 \mathrm{~ms}$. B, Decay kinetics of NMDA-EPSCs $(+40 \mathrm{mV})$ for dual-pathway recordings at layer $4-2 / 3$ and $2 / 3-2 / 3$ pathways. Single-exponential decay function was fitted to NMDA-EPSC traces from peak to $200 \mathrm{~ms}$ after the stimulus artifact, and decay constant $\tau$ was plotted. Filled squares are values for individual cells. Open squares are the mean $\tau$. Error bars indicate SEM. ${ }^{*} p<0.05$ by paired Student's ttest. C, Ifenprodil (Ifen) sensitivity. Top, Schematic of dual-cell recording in control tissue. Bottom left, Example traces of NMDA-EPSC before ( - Ifen) and after ( + Ifen) ifenprodil treatment for dual recordings from both pathways. Calibration: 50 pA, $100 \mathrm{~ms}$. D, Percentage ifenprodilsensitive currents for layer 4-2/3 and 2/3-2/3 pathways. Scatter plot and the mean ( \pm SEM) are presented. $\boldsymbol{E}$, AMPA/NMDA ratio for both pathways. $\boldsymbol{F}$, Example traces of EPSCs recorded at -70 and $+40 \mathrm{mV}$ for AMPA/NMDA ratio in dual-pathway recording configuration. Calibration: 50 $\mathrm{pA}, 20 \mathrm{~ms}$.

arbor in layer $2 / 3$ neurons. For example, $>75 \%$ of inputs from layer 4 terminate on the secondary and tertiary basal dendrites of layer $2 / 3$ pyramidal cells (Lübke et al., 2003) compared with $\sim 70 \%$ of inputs from layer $2 / 3$ pyramidal cells (Feldmeyer et al., 2006). The combination of overlapping synaptic input domains with temporally dissociated critical periods in layer $2 / 3$ neurons
Synaptic segregation and pathway-specific plasticity

Input-specific difference in experience-dependent plasticity is of particular interest because layer 4-2/3 and layer 2/3-2/3 inputs are typically interdigitated across the same regions of the dendritic rats. However, we note that previous studies uniformly focused effects of sensory deprivation, not sensory-induced potentiation, and that critical periods for these two conditions may not proceed in parallel.

Figure 5. Dual-pathway recordings show that SWE-induced plasticity is age and pathway (black) and SWE (green) littermates at P12. B. Example experiment from control and SWE Schematics of experimental recording configuration. 1, Layer 4-2/3 control; 2, layer 2/3-2/3 minimal change at layer 2/3-2/3 synapses ( 4 compared with 2). C.Scatter plot of dual-pan ( $\mathrm{Sr}-\mathrm{mEPSC}$ amplitude for layer $2 / 3-2 / 3$ synapses with inputs from within the spared barrel maturity), the critical period for plasticity at layer $2 / 3-2 / 3$ synmol; 3, layer 4-2/3 SWE; 4, layer 2/3-2/3 SWE. Calibration: 5 pA, 5 ms. SWE leads 

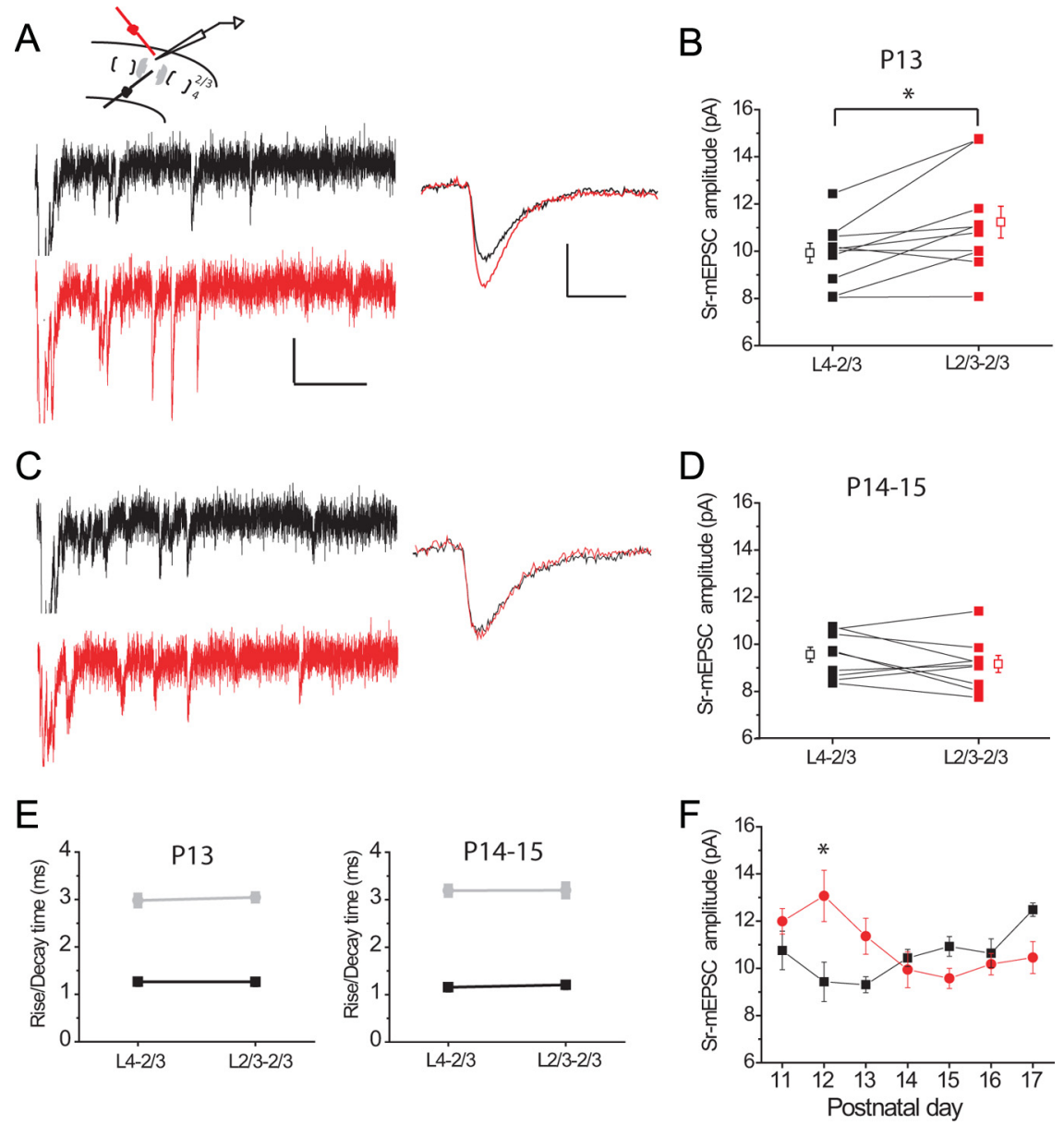

Figure 7. Layer 4-2/3 and 2/3-2/3 synapses show different developmental maturation of Sr-mEPSCs. A, Example traces of evoked Sr-mEPSCs from dual recording of two pathways in a P13 control cell. Top, Schematics of dual recording. Bottom left, Example traces of evoked Sr-mEPSCs at layer 4-2/3 (black) and layer 2/3-2/3 (red) synapses from the same postsynaptic cell. Calibration: $10 \mathrm{pA}, 100 \mathrm{~ms}$. Bottom right, Average traces. Calibration: 5 pA, $5 \mathrm{~ms}$. B, Scatter plots of Sr-mEPSC amplitude recorded at P13 at both pathways. $\boldsymbol{C}$, Example traces of a P14 control cell. Calibration is the same as in $\boldsymbol{A}$. D. The same as in $\boldsymbol{B}$ for P14-P15. $\boldsymbol{E}$, Mean rise time (black) and decay time (gray) of Sr-mEPSCs at P13 (left) and P14-P15 (right). $\boldsymbol{F}$, Mean Sr-mEPSC amplitude from P11 to P17 at layer 4-2/3 and layer 2/3-2/3 pathways from single-pathway experiments. ${ }^{*} p<0.05$.

suggests that dendritic gradients of ion channels that influence electrical coupling of the synapse to the soma (Magee, 1998; Lörincz et al., 2002; Notomi and Shigemoto, 2004; Kole et al., 2006; Johenning et al., 2009; Shah et al., 2010) are unlikely to regulate SWE-induced plasticity.

Previous studies support the notion that the mechanisms underlying in vitro plasticity at layer $4-2 / 3$ and layer $2 / 3-2 / 3$ inputs are distinct. For example, the rules for spike-timing-dependent plasticity (STDP), a prominent hypothesis to explain how coincident presynaptic and postsynaptic activity might lead to synaptic potentiation or depression (Markram et al., 1997; Bi and Poo, 1998; Debanne et al., 1998), has been evaluated at cortical synapses (Feldman, 2000; Banerjee et al., 2009; Zilberter et al., 2009). Previous experiments at layer 2/3-2/3 synapses suggest that longterm depression (LTD) predominates at these contacts (Zilberter et al., 2009). At layer 4-2/3 synapses, STDP follows more conventional rules, in which long-term potentiation (LTP) occurs with presynaptic spiking before postsynaptic depolarization (Banerjee et al., 2009). In addition, spike-timing-dependent LTD at layer 4-2/3 synapses involves presynaptic NMDARs (Bender et al., 2006a,b; Rodríguez-Moreno and Paulsen, 2008) but not at layer 2/3-2/3 inputs (Brasier and Feldman, 2008). Although both layer 4 and layer $2 / 3$ inputs can be modified in vitro in adult tissue using spike-timing plasticity protocols, we find rapid in vivo plasticity is constrained to a discrete window of time during early development.

Synapse-specific critical periods described here were assessed by a postsynaptic measure of synaptic strength, using Sr-desynchronized neurotransmitter release. Presynaptic changes may also contribute to a critical period for experience-dependent response potentiation in vivo.

\section{Developmental changes in EPSC amplitude}

Analysis of Sr-EPSCs in control animals indicates that there is no set point for the amplitude of unitary excitatory synaptic contacts in layer $2 / 3$ cells during early development. For example, EPSC amplitudes at layer 2/3-2/3 synapses become progressively smaller during the second postnatal week. Conversely, control layer 4-2/3 EPSCs become larger by the end of the time windows examined (P17). Remarkably, mean Sr-EPSC amplitudes in control animals could differ by as much as 2 pA across several days, comparable with the maximal effect of SWE at a given postnatal day. In addition, layer 4-2/3 and layer $2 / 3-2 / 3$ inputs were not of similar amplitude on a given postnatal day (P12). Because the effects of SWE were compared with control values at a specific postnatal day (not to an average across multiple days), it is unlikely that our estimate of the timing of these two critical periods is affected by this developmental phenomenon. The regulation of mean synaptic strength at different inputs and across normal development has received considerable attention (Desai et al., 2002), and these data may warrant additional investigation.

\section{CP-AMPARS are not required for plasticity}

Trafficking of CP-AMPARs has been observed after in vitro potentiation (Shi et al., 1999; Hayashi et al., 2000; Zhu et al., 2000; Plant et al., 2006; Clem et al., 2008) (but see Adesnik and Nicoll, 2007 ) as well as in vivo synaptic strengthening in the neocortex, the nucleus accumbens, the ventral tegmental area, and the amygdala (Takahashi et al., 2003; Rumpel et al., 2005; Bellone and Lüscher, 2006; Clem and Barth, 2006; Matsuo et al., 2008). In the barrel cortex, the trafficking of CP-AMPARs has been observed in the spared barrel column after SWE (Clem and Barth, 2006), suggesting that these receptors might have some essential role in the induction or maintenance of plasticity. However, we find that CP-AMPARs are not required for plasticity at layer $4-2 / 3$ synapses, nor is their selective mobilization an adequate explanation for the closure of the critical period.

In addition, it does not appear that CP-AMPARs are ever present in significant amounts at layer 2/3-2/3 synapses, even when these synapses display robust SWE-induced potentiation. The selective trafficking or maintenance of CP-AMPARs to layer 
4-2/3 synapses suggests that plasticity-inducing processes mobilize distinct pools of AMPARs within the same postsynaptic cell (Zhu, 2009). Although the present data do not rule out the possibility that CP-AMPARs might be transiently present (Plant et al., 2006), we think that it is unlikely that they are required for neocortical synaptic strengthening, even at layer 4-2/3 inputs (see also Clem et al. 2010).

Our finding that AMPAR content can be differentially regulated at layer 4 and layer $2 / 3$ inputs is similar to what has been observed at different inputs onto neurons in stellate cells within layer 4 (Zhu, 2009), the lateral geniculate nucleus (Kielland et al., 2009), or the basal amygdala (Humeau et al., 2007), in which distinct pools of AMPAR subunits participate in activitydependent synaptic modifications. Thus, these data provide additional evidence that the identity and activity of the presynaptic input can influence postsynaptic receptor subtype.

\section{Patterns of activity at different excitatory inputs to layer $2 / 3$ pyramidal neurons}

What types of activity are required to drive excitatory synaptic strengthening in vivo? At the developmental ages examined here, layer 4 neurons fire reliably to whisker deflection (Benedetti et al., 2009). However, layer $2 / 3$ neurons do not, and response rates of $<0.5$ spikes per stimulus by single-unit recording in the anesthetized animal have been observed (Benedetti et al., 2009). Thus, it is likely that, at early developmental ages, layer 4-2/3 synapses are activated more robustly by incoming sensory activity than intralaminar inputs onto layer $2 / 3$ pyramidal neurons, which require strong and reliable firing of connected layer $2 / 3$ neurons.

Strong and reliable input from layer 4 neurons observed during the second postnatal week may provoke the earlier maturation and experience-dependent plasticity of layer 4-2/3 synapses. In contrast, layer $2 / 3-2 / 3$ inputs may mature more slowly, consistent with the fact that 2/3-2/3 Sr-EPSCs displayed a longer window for SWE-induced synaptic strengthening. However, it is not consistent with the high NR2B content at layer 4-2/3 synapses, a feature typically seen in more immature synapses (Monyer et al., 1994; Sheng et al., 1994; Flint et al., 1997; Stocca and Vicini, 1998; Tovar and Westbrook, 1999; Barth and Malenka, 2001).

Both layer 4-2/3 and layer 2/3-2/3 inputs can undergo synaptic strengthening in vitro well past the in vivo critical periods described here. For example, spike-timing-dependent LTP can be evoked into adulthood at layer 4-2/3 synapses (Banerjee et al., 2009), and changes in synaptic strength and connectivity have also been observed in mature animals (Cheetham et al., 2007, 2008). Developmental changes in circuit function, such as the emergence of feedback and feedforward inhibition (Kiser et al., 1998; Porter et al., 2001; Swadlow, 2002, 2003; Sun et al., 2006; Helmstaedter et al., 2008), may be important regulators of plasticity in vivo (Hensch et al., 1998; Iwai et al., 2003; Fagiolini et al., 2004; Hensch, 2005). Our data indicate that, in vivo, critical period plasticity is not likely to be regulated solely by the postsynaptic cell or by the proximal/distal location of the synapse on the dendrite. Synapse-specific plasticity might be the result of distinct patterns of activity induced that arrive at layer 4 versus layer $2 / 3$ inputs during the stimulation of sensory inputs or by the synapse-specific presence of plasticity-promoting factors.

\section{References}

Abdul-Ghani MA, Valiante TA, Pennefather PS (1996) $\mathrm{Sr}^{2+}$ and quantal events at excitatory synapses between mouse hippocampal neurons in culture. J Physiol 495:113-125.
Adesnik H, Nicoll RA (2007) Conservation of glutamate receptor 2-containing AMPA receptors during long-term potentiation. J Neurosci 27:4598-4602.

Banerjee A, Meredith RM, Rodríguez-Moreno A, Mierau SB, Auberson YP, Paulsen O (2009) Double dissociation of spike timing-dependent potentiation and depression by subunit-preferring NMDA receptor antagonists in mouse barrel cortex. Cereb Cortex 19:2959-2969.

Barth AL, Malenka RC (2001) NMDAR EPSC kinetics do not regulate the critical period for LTP at thalamocortical synapses. Nat Neurosci 4:235-236.

Barth AL, McKenna M, Glazewski S, Hill P, Impey S, Storm D, Fox K (2000) Upregulation of cAMP response element-mediated gene expression during experience-dependent plasticity in adult neocortex. J Neurosci 20:4206-4216.

Bellone C, Lüscher C (2006) Cocaine triggered AMPA receptor redistribution is reversed in vivo by mGluR-dependent long-term depression. Nat Neurosci 9:636-641.

Bender KJ, Allen CB, Bender VA, Feldman DE (2006a) Synaptic basis for whisker deprivation-induced synaptic depression in rat somatosensory cortex. J Neurosci 26:4155-4165.

Bender VA, Bender KJ, Brasier DJ, Feldman DE (2006b) Two coincidence detectors for spike timing-dependent plasticity in somatosensory cortex. J Neurosci 26:4166-4177.

Benedetti BL, Glazewski S, Barth AL (2009) Reliable and precise neuronal firing during sensory plasticity in superficial layers of primary somatosensory cortex. J Neurosci 29:11817-11827.

Bi GQ, Poo MM (1998) Synaptic modifications in cultured hippocampal neurons: dependence on spike timing, synaptic strength, and postsynaptic cell type. J Neurosci 18:10464-10472.

Brasier DJ, Feldman DE (2008) Synapse-specific expression of functional presynaptic NMDA receptors in rat somatosensory cortex. J Neurosci 28:2199-2211.

Brill J, Huguenard JR (2008) Sequential changes in AMPA receptor targeting in the developing neocortical excitatory circuit. J Neurosci 28:13918-13928.

Carmignoto G, Vicini S (1992) Activity-dependent decrease in NMDA receptor responses during development of the visual cortex. Science 258:1007-1011.

Cheetham CE, Hammond MS, Edwards CE, Finnerty GT (2007) Sensory experience alters cortical connectivity and synaptic function site specifically. J Neurosci 27:3456-3465.

Cheetham CE, Hammond MS, McFarlane R, Finnerty GT (2008) Altered sensory experience induces targeted rewiring of local excitatory connections in mature neocortex. J Neurosci 28:9249-9260.

Chiu SL, Chen CM, Cline HT (2008) Insulin receptor signaling regulates synapse number, dendritic plasticity, and circuit function in vivo. Neuron 58:708-719.

Clem RL, Barth A (2006) Pathway-specific trafficking of native AMPARs by in vivo experience. Neuron 49:663-670.

Clem RL, Celikel T, Barth AL (2008) Ongoing in vivo experience triggers synaptic metaplasticity in the neocortex. Science 319:101-104.

Clem RL, Anggono V, Huganir RL (2010) PICK1 regulates incorporation of calcium-permeable AMPA receptors during cortical synaptic strengthening. J Neurosci 30:6360-6366.

Debanne D, Gähwiler BH, Thompson SM (1998) Long-term synaptic plasticity between pairs of individual CA3 pyramidal cells in rat hippocampal slice cultures. J Physiol 507:237-247.

Desai NS, Cudmore RH, Nelson SB, Turrigiano GG (2002) Critical periods for experience-dependent synaptic scaling in visual cortex. Nat Neurosci 5:783-789.

Diamond ME, Armstrong-James M, Ebner FF (1993) Experience-dependent plasticity in adult rat barrel cortex. Proc Natl Acad Sci U S A 90:2082-2086.

Diamond ME, Huang W, Ebner FF (1994) Laminar comparison of somatosensory cortical plasticity. Science 265:1885-1888.

Fagiolini M, Fritschy JM, Löw K, Möhler H, Rudolph U, Hensch TK (2004) Specific GABAA circuits for visual cortical plasticity. Science 303:1681-1683.

Feldman DE (2000) Timing-based LTP and LTD at vertical inputs to layer II/III pyramidal cells in rat barrel cortex. Neuron 27:45-56.

Feldmeyer D, Lübke J, Sakmann B (2006) Efficacy and connectivity of intracolumnar pairs of layer $2 / 3$ pyramidal cells in the barrel cortex of juvenile rats. J Physiol 575:583-602.

Flint AC, Maisch US, Weishaupt JH, Kriegstein AR, Monyer H (1997) 
NR2A subunit expression shortens NMDA receptor synaptic currents in developing neocortex. J Neurosci 17:2469-2476.

Fox K (1992) A critical period for experience-dependent synaptic plasticity in rat barrel cortex. J Neurosci 12:1826-1838.

Glazewski S, Fox K (1996) Time course of experience-dependent synaptic potentiation and depression in barrel cortex of adolescent rats. J Neurophysiol 75:1714-1729.

Glazewski S, Benedetti BL, Barth AL (2007) Ipsilateral whiskers suppress experience-dependent plasticity in the barrel cortex. J Neurosci 27:3910-3920.

Goda Y, Stevens CF (1994) Two components of transmitter release at a central synapse. Proc Natl Acad Sci U S A 91:12942-12946.

Hayashi Y, Shi SH, Esteban JA, Piccini A, Poncer JC, Malinow R (2000) Driving AMPA receptors into synapses by LTP and CaMKII: requirement for GluR1 and PDZ domain interaction. Science 287:2262-2267.

Helmstaedter M, Staiger JF, Sakmann B, Feldmeyer D (2008) Efficient recruitment of layer $2 / 3$ interneurons by layer 4 input in single columns of rat somatosensory cortex. J Neurosci 28:8273-8284.

Hensch TK (2005) Critical period plasticity in local cortical circuits. Nat Rev Neurosci 6:877-888.

Hensch TK, Fagiolini M, Mataga N, Stryker MP, Baekkeskov S, Kash SF (1998) Local GABA circuit control of experience-dependent plasticity in developing visual cortex. Science 282:1504-1508.

Humeau Y, Reisel D, Johnson AW, Borchardt T, Jensen V, Gebhardt C, Bosch V, Gass P, Bannerman DM, Good MA, Hvalby Ø, Sprengel R, Lüthi A (2007) A pathway-specific function for different AMPA receptor subunits in amygdala long-term potentiation and fear conditioning. J Neurosci 27:10947-10956.

Isaac JT, Crair MC, Nicoll RA, Malenka RC (1997) Silent synapses during development of thalamocortical inputs. Neuron 18:269-280.

Iwai Y, Fagiolini M, Obata K, Hensch TK (2003) Rapid critical period induction by tonic inhibition in visual cortex. J Neurosci 23:6695-6702.

Johenning FW, Beed PS, Trimbuch T, Bendels MH, Winterer J, Schmitz D (2009) Dendritic compartment and neuronal output mode determine pathway-specific long-term potentiation in the piriform cortex. J Neurosci 29:13649-13661.

Kielland A, Bochorishvili G, Corson J, Zhang L, Rosin DL, Heggelund P, Zhu JJ (2009) Activity patterns govern synapse-specific AMPA receptor trafficking between deliverable and synaptic pools. Neuron 62:84-101.

Kiser PJ, Cooper NG, Mower GD (1998) Expression of two forms of glutamic acid decarboxylase (GAD67 and GAD65) during postnatal development of rat somatosensory barrel cortex. J Comp Neurol 402:62-74.

Kole MH, Hallermann S, Stuart GJ (2006) Single Ih channels in pyramidal neuron dendrites: properties, distribution, and impact on action potential output. J Neurosci 26:1677-1687.

Kumar SS, Huguenard JR (2003) Pathway-specific differences in subunit composition of synaptic NMDA receptors on pyramidal neurons in neocortex. J Neurosci 23:10074-10083.

Kumar SS, Bacci A, Kharazia V, Huguenard JR (2002) A developmental switch of AMPA receptor subunits in neocortical pyramidal neurons. J Neurosci 22:3005-3015.

Lefort S, Tomm C, Floyd Sarria JC, Petersen CC (2009) The excitatory neuronal network of the $\mathrm{C} 2$ barrel column in mouse primary somatosensory cortex. Neuron 61:301-316.

Lendvai B, Stern EA, Chen B, Svoboda K (2000) Experience-dependent plasticity of dendritic spines in the developing rat barrel cortex in vivo. Nature 404:876-881.

Lörincz A, Notomi T, Tamás G, Shigemoto R, Nusser Z (2002) Polarized and compartment-dependent distribution of HCN1 in pyramidal cell dendrites. Nat Neurosci 5:1185-1193.

Lu HC, Gonzalez E, Crair MC (2001) Barrel cortex critical period plasticity is independent of changes in NMDA receptor subunit composition. Neuron 32:619-634.

Lübke J, Roth A, Feldmeyer D, Sakmann B (2003) Morphometric analysis of the columnar innervation domain of neurons connecting layer 4 and layer 2/3 of juvenile rat barrel cortex. Cereb Cortex 13:1051-1063.

Magee JC (1998) Dendritic hyperpolarization-activated currents modify the integrative properties of hippocampal CAl pyramidal neurons. J Neurosci 18:7613-7624.

Maravall M, Stern EA, Svoboda K (2004) Development of intrinsic properties and excitability of layer $2 / 3$ pyramidal neurons during a critical period for sensory maps in rat barrel cortex. J Neurophysiol 92:144-156.
Markram H, Lübke J, Frotscher M, Sakmann B (1997) Regulation of synaptic efficacy by coincidence of postsynaptic APs and EPSPs. Science 275:213-215.

Matsuo N, Reijmers L, Mayford M (2008) Spine-type-specific recruitment of newly synthesized AMPA receptors with learning. Science 319:1104-1107.

Monyer H, Burnashev N, Laurie DJ, Sakmann B, Seeburg PH (1994) Developmental and regional expression in the rat brain and functional properties of four NMDA receptors. Neuron 12:529-540.

Notomi T, Shigemoto R (2004) Immunohistochemical localization of Ih channel subunits, HCN1-4, in the rat brain. J Comp Neurol 471:241-276.

Plant K, Pelkey KA, Bortolotto ZA, Morita D, Terashima A, McBain CJ, Collingridge GL, Isaac JT (2006) Transient incorporation of native GluR2-lacking AMPA receptors during hippocampal long-term potentiation. Nat Neurosci 9:602-604.

Porter JT, Johnson CK, Agmon A (2001) Diverse types of interneurons generate thalamus-evoked feedforward inhibition in the mouse barrel cortex. J Neurosci 21:2699-2710.

Rodríguez-Moreno A, Paulsen O (2008) Spike timing-dependent longterm depression requires presynaptic NMDA receptors. Nat Neurosci 11:744-745.

Rumpel S, LeDoux J, Zador A, Malinow R (2005) Postsynaptic receptor trafficking underlying a form of associative learning. Science 308:83-88.

Shah MM, Hammond RS, Hoffman DA (2010) Dendritic ion channel trafficking and plasticity. Trends Neurosci 33:307-316.

Sheng M, Lee SH (2001) AMPA receptor trafficking and the control of synaptic transmission. Cell 105:825-828.

Sheng M, Cummings J, Roldan LA, Jan YN, Jan LY (1994) Changing subunit composition of heteromeric NMDA receptors during development of rat cortex. Nature 368:144-147.

Shi SH, Hayashi Y, Petralia RS, Zaman SH, Wenthold RJ, Svoboda K, Malinow R (1999) Rapid spine delivery and redistribution of AMPA receptors after synaptic NMDA receptor activation. Science 284:1811-1816.

Shoykhet M, Land PW, Simons DJ (2005) Whisker trimming begun at birth or on postnatal day 12 affects excitatory and inhibitory receptive fields of layer IV barrel neurons. J Neurophysiol 94:3987-3995.

Stern EA, Maravall M, Svoboda K (2001) Rapid development and plasticity of layer 2/3 maps in rat barrel cortex in vivo. Neuron 31:305-315.

Stocca G, Vicini S (1998) Increased contribution of NR2A subunit to synaptic NMDA receptors in developing rat cortical neurons. J Physiol 507:13-24.

Sun QQ, Huguenard JR, Prince DA (2006) Barrel cortex microcircuits: thalamocortical feedforward inhibition in spiny stellate cells is mediated by a small number of fast-spiking interneurons. J Neurosci 26:1219-1230.

Swadlow HA (2002) Thalamocortical control of feed-forward inhibition in awake somatosensory "barrel” cortex. Philos Trans R Soc Lond B Biol Sci 357:1717-1727.

Swadlow HA (2003) Fast-spike interneurons and feedforward inhibition in awake sensory neocortex. Cereb Cortex 13:25-32.

Swanson GT, Kamboj SK, Cull-Candy SG (1997) Single-channel properties of recombinant AMPA receptors depend on RNA editing, splice variation, and subunit composition. J Neurosci 17:58-69.

Takahashi T, Svoboda K, Malinow R (2003) Experience strengthening transmission by driving AMPA receptors into synapses. Science 299:1585-1588.

Tovar KR, Westbrook GL (1999) The incorporation of NMDA receptors with a distinct subunit composition at nascent hippocampal synapses in vitro. J Neurosci 19:4180-4188.

Wu G, Malinow R, Cline HT (1996) Maturation of a central glutamatergic synapse. Science 274:972-976.

Xu-Friedman MA, Regehr WG (1999) Presynaptic strontium dynamics and synaptic transmission. Biophys J 76:2029-2042.

Zhu JJ (2009) Activity level-dependent synapse-specific AMPA receptor trafficking regulates transmission kinetics. J Neurosci 29:6320-6335.

Zhu JJ, Esteban JA, Hayashi Y, Malinow R (2000) Postnatal synaptic potentiation: delivery of GluR4-containing AMPA receptors by spontaneous activity. Nat Neurosci 3:1098-1106.

Zilberter M, Holmgren C, Shemer I, Silberberg G, Grillner S, Harkany T, Zilberter Y (2009) Input specificity and dependence of spike timingdependent plasticity on preceding postsynaptic activity at unitary connections between neocortical layer 2/3 pyramidal cells. Cereb Cortex 19: $2308-2320$. 